\title{
Self-Perceived Incompetence in Psychiatric Practice of Practitioners from Southern Thailand: One Year Following Graduation
}

\section{Chonnakarn JATCHAVALA* and Jarurin PITANUPONG}

\author{
Department of Psychiatry, Faculty of Medicine, Prince of Songkla, Songkhla 90110, Thailand
}

('Corresponding author’s e-mail: jchonnak@medicine.psu.ac.th)

Received: 29 May 2020, Revised: 25 January 2021, Accepted: 31 January 2021

\begin{abstract}
General psychiatric training is one of the essential requirements for all Thai medical doctors, as declared by the Medical Council of Thailand in 2012. Hence, psychiatric training for medical students must be fulfilled to achieve these requirements. This study was designed to examine the change of subjects and the self-perceived incompetence in psychiatric practice of a cohort of medical doctors who graduated in the academic year of 2017, in concerns to their practices one year after graduation. Most participants were female doctors, with an average age of 25.7 years, and were working in Southern Thailand. Compared with 1 year prior, they showed a statistically significant frequency of physical disorders and increasing stress from their work. The largest topic of psychiatric practice, for which they were statistically more concerned with, concerned child and adolescent psychiatry. Self-perceived incompetence in both diagnosis and treatment significantly increased from graduation, with the exceptions of diagnoses of mental retardation, attention deficit hyperactivity, and tics/Tourette's disorder. Substance-related disorders in adults, along with basic psychological support, were found to be general practice self-perceived incompetence, at both outpatient clinics and inpatient units. However, practice in adult outpatients at psychiatric clinics mostly demonstrated significantly more self-perceived competence. Moreover, emergency care, especially concerning patient suicide and multi-disciplinary practice, was shown to have increasing self-perceived competence among general practitioners having worked for a year following graduation. This information should be used as feedback for stakeholders in both medical education and mental health care.
\end{abstract}

Keywords: Competency, Psychiatry, General practitioner, Medical education

\section{Introduction}

The World Health Organization (WHO) has announced that the burden of mental illness remains on the rise, having significant impact on health in all countries around the world [1]. The gap between the need for psychiatric treatment and being able to provide it is wide, especially in low- and middle-income countries, including Thailand $[1,2]$. It was reported that 76 to $85 \%$ of patients had received no psychiatric treatment [1]. Thus, WHO's Mental Health Gap Action Program (mhGAP), which was publicized in 2008, declared the need for global collaboration in the use of evidence-based technical guidance and training programs to expand these services. One of the strategies is to build up the capacity of nonspecialized health-care providers, including general practitioners (GP) or M.D. graduates in Thailand, to create an integrated health care system [2].

Existing mental illness-related stigma in the healthcare system has been identified as a barrier to accessing psychiatric treatment and allowing psychological recovery, along with having an underestimation of physical illnesses, if patients have a record of any "psychiatric disorders" [3]. Between 20 - $25 \%$ of visits to general practitioners are related to mental health problems in Quebec, Canada [4]. We used to believe that contact with professional health care providers, especially medical 
doctors, should increase the potential opportunity for recognizing and identifying suicides, as well as other serious psychiatric illnesses among patients [5]. However, $82 \%$ of suicidal patients in the UK consulted a GP 12 months before they committed suicide, and over a third had seen a psychiatrist, whilst only $2 \%$ of them had received counseling [6]. In Canada, more than $50 \%$ of general practitioners reported that they did not have the resources required within the mental health field [4]. Thus, it seems there are no medical education programs, nor WHO requirements from non-psychiatrist medical doctors, for the WHO's Mental Health Gap Action Programs (mhGAP).

A study conducted in India found that $98.5 \%$ of Indian medical practitioners in primary care reported that they needed to be better trained and oriented for psychiatry [7]. Almost all of them stated that mental illness is of serious concern. However, only $79.7 \%$ of them claimed that they did not recognize how to deal with psychiatric patients properly. In another research in India, it was reported that general practitioners felt competent, as well as confident, in recognizing the signs and symptoms of simple depression, anxiety, and psychosis, but the chief complaints they had in general practice concerned psychosomatic problems, such as sleep problems $(84.2 \%)$, appetite disturbances $(84.2 \%)$, abnormal and irrational fears $(84.2 \%)$, problems in sexual activity $(72.9 \%)$, drug addictions $(62.41 \%)$, and problems of forgetfulness $(66.17 \%)$ [6]. In addition, they noticed that psychiatric referrals were made with reluctance. This was due to social stigma among psychiatric patients and the doctors' dissatisfaction with their own competence in treating psychiatric illnesses. In Canada, family medicine groups, along with network clinics, reported that they were not getting significant outcomes from psychiatric services, even though they had tried to improve service integration by implementing local general practitioners into programs [4]. Additionally, mental disorders are mainly still treated during primary care by general practitioners (GPs), even though the ability to detect, diagnose, and treat patients with mental disorders is often considered unsatisfactory [8].

Although medical programs, along with training programs, are different among Eastern and Western countries, non-psychiatric medical practitioners are still concerned with managing patients with mental health problems in their practices. Hence, psychiatric training for medical students must be fulfilled to achieve these requirements. General psychiatric training is one of the essential requirements for all Thai medical doctors, as declared by the Medical Council of Thailand in 2012 [9].

However, psychiatric training for general practitioners may promote insufficient self-perceived competence within the first year after graduation. Keeping this in mind, Thai medical education for undergraduates should consider up-to-date curricula for both responses and recommendations for new M.D. graduates and follow them up 1 year after they have completed their psychiatric training as general practitioners.

Additionally, no prior study on either competence or concerning psychiatric training among either medical graduates or general practitioners has been reported in Thailand. Thus, datasets from surveys should be created to provide more information, as this will be beneficial for both medical education and mental health care services, especially in Southern Thailand.

This study was the second phase (phase II) of a cohort study; the first phrase (phrase I) was a descriptive, cross-sectional survey of all M.D. graduates who were approached at graduation rehearsal for the first data collection [10]. In the academic year of 2017, medical doctors, who graduated from the Prince of Songkla University, perceived their own self-perceived incompetence towards outpatient training at psychiatric clinics and for the prescription of psychiatric drugs. They also demonstrated that they were most concerned with emergency management and child psychiatric practice. Additionally, these doctors stated they felt the most incompetence towards patients with substance-related disorders [10].

This phase of the cohort study aimed to examine the change of subjects and the self-perceived incompetence scales of psychiatric practice in medical doctors who graduated in the academic year of 2017, concerning their general practices after one-year of graduation. 


\section{Materials and methods}

\section{Measurement}

1) Personal information and details regarding their medical career was approved by 3 experts.

2) Subjects and self-perceived competence of psychiatric training concerning general practices. The subjects followed topics and objectives of the psychiatry curriculum for externs, endorsed by the Faculty of Medicine, Prince of Songkla University. A self-perceived competence scale was inside the items of the self-administered questionnaires. This was scored from $1-4$. Score 1 meant the participants felt no concern about their competence at all, and score 4 meant they were concerned with and self-perceived total incompetence in psychiatric practice.

\section{Data collection}

Researchers asked for permission from the Student Affairs Division on behalf of graduation rehearsal (18 September 2018) for the first phase of data collection. Every research-assistant was trained by the researchers before administering the questionnaires. Participants were approached by researchers, who were psychiatrists or research assistants, and they completed the self-administered questionnaires after their usual activities. The completed questionnaires were kept in sealed envelopes for confidentiality and tagged with a concealed code for the second phase analysis [10].

Regarding the second phase, the researchers made inquiries to the Medical Education Division as they send workload and competence feedback to all M.D.s who graduate every year. Self-administered questionnaires were sent to every Doctor of Medicine that had completed the questionnaire of the phase I data collection by mail. The second phase data collection was a self-administered questionnaire which was attached to these documents. This was sent back by the participants themselves to the division during the periods of June to August 2019. All questionnaires were checked for completeness and consistency; double data entry was entered monthly using EpiData software.

\section{Data analysis}

All statistical procedures were performed using the R software package.

1) Descriptive statistics were presented as demographic characteristics of the samples in frequency, percentage, articulate mean, and standard deviation.

2) Correlation analysis was conducted by Chi-square and Fisher's exact test.

\section{Results and discussion}

\section{Personal information, workload, and life burden}

From the 31 general practitioners (GPs) who graduated in the academic year of 2017 and participated one year after (Table 1), most were female $(58.1 \%)$, with an average age of 25.7 years. Their workplaces were mostly located in Southern Thailand $(87.1 \%)$. As per Table 2, from these participants, $82.1 \%$ of the GPs reported significant stress from their work, which increased statistically (Chi-square's $\mathrm{p}$-value $=0.000)$. Additionally, $26.7 \%$ of them stated that they had physical diseases, increased from 11.1 $\%(p$-value $=0.041)$. Although mental disorders did not surge significantly statistically, $6.9 \%$ of participants following graduation reported these, compared with $0.9 \%$ one year prior. 
http://wjst.wu.ac.th

Table 1 Personal information.

\begin{tabular}{llc}
\hline \multirow{2}{*}{ Personal information } & \multicolumn{1}{c}{ N (\%) } \\
\cline { 2 - 3 } & $\begin{array}{l}\text { Graduation } \\
(\mathbf{n}=\mathbf{1 1 8})\end{array}$ & $\begin{array}{l}\text { One-year follow up } \\
(\mathbf{n}=\mathbf{3 1})\end{array}$ \\
\hline Gender & $42(35.6)$ & $13(41.9)$ \\
Male & $76(64.4)$ & $18(58.1)$ \\
Female & & \\
\hline Age & $24.5 \pm 0.6(23-27)$ & $25.7 \pm 0.7(25-27)$ \\
Mean \pm SD (Minimum-Maximum) & & \\
\hline Workplace & $55(46.6)$ & $20(64.5)$ \\
Songkhla & $37(31.4)$ & $5(16.1)$ \\
Other provinces in Southern Thailand & $14(11.9)$ & $2(6.5)$ \\
The south border provinces & $12(10.2)$ & $4(12.9)$ \\
Other parts of Thailand & & \\
\hline
\end{tabular}

Table 2 Comparison of workload and life burden between M.D. graduates and one year following.

\begin{tabular}{|c|c|c|c|}
\hline \multirow{2}{*}{ Workload and life burden } & \multicolumn{2}{|c|}{$\mathbf{N}(\%)$} & \multirow{2}{*}{$\begin{array}{l}\text { P-value } \\
\text { Fisher's exact test }\end{array}$} \\
\hline & $\begin{array}{l}\text { Graduation } \\
(n=118)\end{array}$ & $\begin{array}{l}\text { One-year follow-up } \\
(n=31)\end{array}$ & \\
\hline Perceived stress from work & & & $0.000^{\mathrm{a}}$ \\
\hline No & $109(92.4)$ & $5(17.9)$ & \\
\hline Yes & $9(7.6)$ & $23(82.1)$ & \\
\hline Work time/week $($ Mean \pm SD) & - & $63.6 \pm 27.1$ & \\
\hline Physical disorder* & & & 0.041 \\
\hline No & $104(88.9)$ & $22(73.3)$ & \\
\hline Yes & $13(11.1)$ & $8(26.7)$ & \\
\hline Psychological disorder & & & 0.102 \\
\hline No & $115(99.1)$ & $27(93.1)$ & \\
\hline Yes & $1(0.9)$ & $2(6.9)$ & \\
\hline
\end{tabular}

Note: ${ }^{a}$ Chi-square's p-value; * Significant p-value

\section{Self-perceived incompetence in psychiatric practice}

One year following M.D. graduation, general practitioners' self-perceived incompetence mostly concerned child psychiatric practice. Treatment of tics/ Tourette's disorder and functional enuresis (65.5 and $65.5 \%$, respectively) and diagnosis of learning disorders $(68.9 \%)$ were the most common issues they were concerned with (Table 3).

The respondents also reported that they mostly self-perceived incompetence in giving psychological support in both inpatient units and outpatient clinics (48.3 and $55.2 \%$, respectively). Moreover, substance-related disorders were the mental disorders they felt most concerned about in adult patients. In the emergency room, the general practitioners reported their own perception of incompetence in dealing with aggressive and violent patients $(51.7 \%)$. 
However, the GPs stated they perceived less self-perceived incompetence in the history-taking of psychiatric issues $(10.0 \%)$ and in outpatient clinic practice $(17.2 \%$ for diagnosis and $13.8 \%$ for treatment, respectively). Depressive disorder $(10.3 \%)$ and anxiety disorder $(13.8 \%)$ were the most common mental diseases they felt competent in handling.

Table 3 Comparison of self-perceived incompetence in psychiatric practice between M.D. graduation and one year follow-up.

\begin{tabular}{|c|c|c|c|}
\hline \multirow[t]{2}{*}{ Self-perceived incompetence in psychiatric practice } & \multicolumn{2}{|c|}{$\begin{array}{c}\text { Self-perceived incompetence } \\
\text { (score 3 - 4) } \\
\text { N (\%) }\end{array}$} & \multirow{2}{*}{$\begin{array}{l}\text { P-value } \\
\text { Fisher's } \\
\text { exact test }\end{array}$} \\
\hline & $\begin{array}{l}\text { Graduation } \\
(\mathrm{n}=118)\end{array}$ & $\begin{array}{l}\text { One year follow-up } \\
(\mathrm{n}=31)\end{array}$ & \\
\hline \multicolumn{4}{|l|}{$\begin{array}{l}\text { History-taking, physical, and mental status } \\
\text { examination }\end{array}$} \\
\hline 1. History-taking and physical examination & $10(9.0)$ & $3(10.0)$ & 1 \\
\hline 2. Mental status examination & $18(16.4)$ & $7(23.3)$ & 0.422 \\
\hline \multicolumn{4}{|l|}{ Outpatient unit care } \\
\hline 3. Overall diagnosis at outpatient unit & $23(19.5)$ & $5(17.2)$ & 1 \\
\hline 4. Depressive disorder diagnosis & $18(15.3)$ & $3(10.3)$ & 0.767 \\
\hline 5. Bipolar disorder diagnosis & $25(21.2)$ & $6(20.7)$ & 1 \\
\hline 6. Psychotic disorder diagnosis & $27(23.1)$ & $7(24.1)$ & 1 \\
\hline 7. Organic mental disorder diagnosis & $31(26.3)$ & $7(24.1)$ & 1 \\
\hline 8. Anxiety disorder diagnosis & $18(15.2)$ & $4(13.8)$ & 1 \\
\hline 9. Overall patient unit treatment & $20(16.9)$ & $4(13.8)$ & 0.786 \\
\hline 10. Pharmacotherapy & $38(32.2)$ & $11(37.9)$ & 0.661 \\
\hline 11. Basic Psychological Support & $33(27.9)$ & $16(55.2)$ & $0.008 *$ \\
\hline \multicolumn{4}{|l|}{ Child and adolescent psychiatry } \\
\hline 12. Overall diagnosis in children and adolescents & $43(36.4)$ & $12(41.4)$ & 0.671 \\
\hline 13. Attention deficit hyperactivity diagnosis & $27(22.9)$ & $12(40.0)$ & 0.066 \\
\hline 14. Autistic spectrum diagnosis & $34(29.1)$ & $15(50.0)$ & $0.049 *$ \\
\hline 15. Tic and Tourette disorder diagnosis & $33(27.9)$ & $13(44.8)$ & 0.116 \\
\hline 16. Functional enuresis diagnosis & $33(27.9)$ & $17(58.6)$ & $0.004 *$ \\
\hline 17. Learning disorder diagnosis & $38(32.2)$ & $20(68.9)$ & $0.001 *$ \\
\hline 18. Mental retardation diagnosis & $40(33.9)$ & $16(55.2)$ & 0.053 \\
\hline 19. Overall treatment in children and adolescents & $40(33.9)$ & $18(60.0)$ & $0.012 *$ \\
\hline 20. Attention deficit hyperactivity treatment & $29(25.0)$ & $18(60.0)$ & $0.001 *$ \\
\hline 21. Autistic spectrum treatment & $41(34.7)$ & $17(56.7)$ & $0.036^{*}$ \\
\hline 22. Tic and Tourette disorder treatment & $40(33.9)$ & $19(65.5)$ & $0.003 *$ \\
\hline 23. Functional enuresis treatment & $43(36.4)$ & $19(65.5)$ & $0.006^{*}$ \\
\hline 24. Learning disorder treatment & $44(37.3)$ & $18(62.1)$ & $0.021 *$ \\
\hline 25. Mental retardation treatment & $45(38.1)$ & $17(58.6)$ & 0.059 \\
\hline \multicolumn{4}{|l|}{ Inpatient unit care } \\
\hline 26. Overall inpatient unit care & $22(18.6)$ & $7(24.1)$ & 0.602 \\
\hline 27. Pharmacotherapy & $35(29.7)$ & $10(34.5)$ & 0.656 \\
\hline 28. Basic psychological support & $29(24.6)$ & $14(48.3)$ & $0.021 *$ \\
\hline \multicolumn{4}{|l|}{ Emergency psychiatry } \\
\hline 29. Overall emergency care & $46(38.9)$ & $10(34.5)$ & 0.831 \\
\hline 30. Suicide & $56(47.9)$ & $13(44.8)$ & 0.837 \\
\hline 31. Aggressive behavior and violence & $59(50.4)$ & $15(51.7)$ & 1 \\
\hline \multicolumn{4}{|l|}{ Miscellaneous } \\
\hline 32. Community-based care & $20(16.9)$ & $6(21.4)$ & 0.587 \\
\hline
\end{tabular}




\begin{tabular}{llcl}
\hline & \multicolumn{1}{c}{$\begin{array}{c}\text { Self-perceived incompetence } \\
\text { (score 3 - 4) } \\
\text { N (\%) }\end{array}$} & $\begin{array}{l}\text { P-value } \\
\text { Fisher's } \\
\text { exact test }\end{array}$ \\
\cline { 2 - 3 } & \multicolumn{2}{c}{$\begin{array}{c}\text { One year follow-up } \\
\text { (n=31) }\end{array}$} & 0.366 \\
\hline 33. Substance addiction & $33(27.9)$ & $11(37.9)$ & 1 \\
34. Alcohol dependence & $28(23.7)$ & $7(24.1)$ & 0.795 \\
35. Alcohol withdrawal syndrome & $22(18.6)$ & $6(20.7)$ & 0.287 \\
36. Delirium & $18(15.3)$ & $7(23.3)$ & 1 \\
37. Psychoeducation & $31(26.3)$ & $8(27.6)$ & 0.423 \\
38. Therapeutic relationships & $20(16.9)$ & $7(24.1)$ & 1 \\
39. Multidisciplinary team & $17(14.4)$ & $4(13.8)$ & \\
\hline
\end{tabular}

Note: ${ }^{*}$ p-value $<0.05$

Compared with one year prior, practice in child psychiatry was statistically significant in increased self-perceived incompetence ( $p$-value $<0.05$ ), in terms of Autistic spectrum, Functional enuresis diagnosis, and Learning disorders, for both diagnosis and treatment. Even though self-perceived incompetence in the diagnosis of attention deficit hyperactivity, mental retardation, and tics/Tourette's disorder were not significantly increased statistically, the treatment of attention deficit hyperactivity and tics/Tourette's disorder were ( $\mathrm{p}$-value $=0.001$ and 0.003 , respectively). In addition, the GPs reported that they perceived incompetence in giving basic psychological support to patients at both outpatient clinics and inpatient units ( $\mathrm{p}$-value $=0.008$ and 0.021 , respectively).

\section{Discussion}

According to the survey, the statistically significant surge in percentage of physical disorders and stress perceived from work was of considerable concern among young medical doctors. Due to the rise in mental disorders, from 0.9 to $6.9 \%$ within 1 year, embracing resources for stress recovery and balancing private life with workload should be one of the topics in medical education, so as to raise well-being and build resilience [11]. A study in Thai medical doctors revealed that quality of sleep and family relationship were promoting factors of resilience, whereas Thai GPs' workload significantly disturbed them [12]. Knowledge of psychiatry has been essential for medical students, not only for patients' psychiatric problems, but also to prevent problems in the general population, either mentally or mentally combined with physically. These issues have been challenges for medical instructors in the modification of curricula for these purposes [13].

The same can be said in Germany and Australia, where child and adolescent psychiatry teaching in medical schools was comparatively small and not consistent with the size of clinical problems [13,14]. This study in Thailand showed that the GPs mostly self-perceived incompetence, and this had significantly increased. Therefore, increased involvement of academic departments of child and adolescent psychiatry in training Thai medical students, particularly between pediatric departments and child psychiatry departments, should be considered. In practice, pediatrists and child psychiatrists may have to play more of a role in consultation and referral to reassure and encourage the GPs in both diagnosis and treatment $[14,15]$.

As well as practice in emergency psychiatry, aggressive and violent patients were of concern for the Thai GPs. Substance-related disorders were of the most concern in adult psychiatry, with most cases of aggressive patients presenting at the ER. GPs should be trained to realize their abilities and limitations, together with the creation of a criteria for referring patients to more competent professionals [16]. Moreover, "insecurity" is the cause of their apprehension. Thus, hospitals should manage security staff to respond to unexpected, violent situations immediately, to assist ER personnel if needed [16].

Basic psychological support given to patients, both at outpatient psychiatric clinics and inpatient units, had more self-perceived- competence than that of pharmacotherapy from those who graduated in the academic year of 2017. However, there was a significant increase in self-perceived incompetence 
when they were GPs a year after graduation. The reasons for this may be that most psychiatric medical students counseled fewer patients under the supervision of psychiatric instructors [17]. To enhance selfperceived competence, mental health personnel should assist them during their first year after M.D. graduation. Multidisciplinary collaboration was a strength of these GPs since they had graduated [10]. Hence, more psychological support from multidisciplinary teams should be embraced into psychiatric treatments, to encourage the GPs for their self-perception of competence.

\section{Limitation}

According to uncontrollable delay in data collection, such as in practicing for post-training ceremonies, the researcher had to postpone the date of all data collection up until the delayed graduation ceremony. However, the methodology of a 1 year follow-up ought to be fixed to enhance the validity of the potential results. For these reasons, the response rate was too low, and may not illustrate the whole reality in Thailand. Due to these factors, further studies should be designed for unexpected obstacles to data collection. Online surveys may be more convenient than offline ones in such situations. Additionally, this study was only conducted at a medical school in Southern Thailand. To improve Thai M.D. curricula and general practice enrichment, researchers should collect data nationwide.

\section{Conclusions}

Southern Thai general practitioners who graduated 1 year ago had statistically more physical disease and stress compared to when they were M.D. graduates. They stated that they felt significantly more selfperceived incompetence in psychiatric practice for children and adolescents and in basic psychological support for adult patients. However, self-perceived competency was reported to be increased in outpatient practice at psychiatric clinics, emergency management, and in multi-disciplinary care.

\section{Acknowledgements}

This project was endorsed by the ethics committee and was fully funded by the Faculty of Medicine, Prince of Songkla University, Thailand (REC- 61-1173-1). Regarding the Student Affairs Division, the Post-Graduation Education Division, the Medical Education Division, Ms. Kruewan Jongborwanwiwat, and Mrs. Nisan Werachattawanand, both authors are eternally grateful for their helpful collection of data and statistical analysis. Moreover, we genuinely appreciate the International Affairs unit of the Faculty of Medicine for the proof-reading of the English by Mr. Andrew Tait. The study has been accepted for poster presentation (Education in Psychiatry) at the $20^{\text {th }}$ WPA World Congress of Psychiatry, which will take place in Bangkok, Thailand, 10 - 13 March 2021.

\section{References}

[1] World Health Organization (WHO), Available at: http://www.who.int/mediacentre/factsheets/ fs396/en, accessed March 2018.

[2] World Health Organization (WHO), Available at: http://www.who.int/mental_health/mhgap/en, accessed March 2018.

[3] S Knaak, E Mantler and A Szeto. Mental illness-related stigma in healthcare: Barriers to access and care and evidence-based solutions. Healthc. Manage. Forum. 2017; 30, 111-6.

[4] M Fleury, L Farand, D Aube and A Imboua. Management of mental health problems by general practitioners in Quebec. Can. Fam. Physician. 2012; 58, 732-8.

[5] G Leavey, M Rosato, K Galway, L Hughes, S Mallon and J Rondon. Patterns and predictors of help-seeking contacts with health services and general practitioner detection of suicidality prior to suicide: a cohort analysis of suicides occurring over a two-year period. BMC Psychiatry 2016; 16, 120. 
[6] A Pearson, P Saini, DD Cruz, C Miles, D While, N Swinson, A Williams, J Shaw, L Appleby and N Kapur. Primary care contact prior to suicide in individuals with mental illness. Br. J. Gen. Pract. 2009; 59, 825-32

[7] RK Chaudhary and BP Mishra. Knowledge and practices of general practitioners regarding psychiatric problems. Ind. Psychiat. J. 2009; 18, 22-6.

[8] M Fleury, A Imboua, D Aube, L Farand and Y Lambert. General practitioners' management of mental disorders: a rewarding practice with considerable obstacles. BMC Fam. Pract. 2012; 13, 19.

[9] The Medical Council of Thailand, Available at: http://www.tmc.or.th/tmc_training.php, accessed March 2018.

[10] C Jatchavala and J Sangkool. A survey concerning the psychiatric practices of medical doctors, who graduated from Prince of Songkla University in 2017. J. Ment. Health. Thai. 2019; 27, 52-64.

[11 C Bergmann, T Muth and A Loerbroks. Medical students' perceptions of stress due to academic studies and its interrelationships with other domains of life: A qualitative study. Med. Educ. Online $2019 ; 24,1603526$.

[12] C Jatchavala and J Pitanupong. Resilience in Medical Doctors within the Areas of the Southern Thailand Insurgency. Siriraj Med J. 2019; 71, 228-33.

[13] SM Manohari, PR Johnson and RB Galgali. How to teach psychiatry to medical undergraduates in India? A model. Indian. J. Psychol. Med. 2013; 35, 23-8.

[14] R Frank and F Frank. Teaching child and adolescent psychiatry to undergraduate medical students a survey in German-speaking countries. Child. Adolesc. Psychiat. Ment. Health 2010; 4, 21.

[15] M Sawyer and F Giesen. Undergraduate teaching of child and adolescent psychiatry in Australia: survey of current practice. Aust. NZ. J. Psychiat. 2007; 41, 675-81.

[16] M Sen and SG Honavar. It's a doc's life: Workplace violence against doctors. Indian. J. Ophthalmol. 2019; 67, 981-4.

[17] S Gupta and J Shaw. Development of medication-related counselling skills in senior medical students: a checklist-based approach. BMC Med. Educ. 2019; 19, 335. 